\title{
D005
}

\section{Integrating Basin/Petroleum System Analysis and Play/Prospect Assessment}

\section{R. Sinding-Larsen* (Norwegian University of Science \& Technology)}

\section{SUMMARY}

Petroleum system modeling is a vital component of exploration that contributes to volumetric and risk assessment at basin, play, and prospect scales. It can be applied during all stages of exploration, from regional charge evaluations for frontier basins with little or no well control to complex charge evaluations for individual prospects or fields within thoroughly explored areas.

This paper presents integrated workflows that capture the results from basin and petroleum system analysis and populate play and prospect databases with information on potential hydrocarbon accumulations, including volumetric dependency among accumulations as well as leak connections among hydrocarbon pools.

Alternative scenarios for the evolution of the petroleum system are used for capturing prospect risk and hydrocarbon entrapment uncertainty. Adding this stochastic dimension to the play and prospect databases provides a more robust understanding of the full range of possible outcomes that if used properly may provide significant competitive advantage. 


\begin{abstract}
Petroleum system modeling is a vital component of exploration that contributes to volumetric and risk assessment at basin, play, and prospect scales. It can be applied during all stages of exploration, from regional charge evaluations for frontier basins with little or no well control to complex charge evaluations for individual prospects or fields within thoroughly explored areas. This paper presents integrated workflows that capture the results from basin and petroleum system analysis and populate play and prospect databases with information on potential hydrocarbon accumulations, including volumetric dependency among accumulations as well as leak connections among hydrocarbon pools. Alternative scenarios for the evolution of the petroleum system are used for capturing prospect risk and hydrocarbon entrapment uncertainty. Adding this stochastic dimension to the play and prospect databases provides a more robust understanding of the full range of possible outcomes that if used properly may provide significant competitive advantage.
\end{abstract}

